\title{
VII
}

\section{DIAGNOSIS AND TREATMENT OF URETHRITIS AND CERVICITIS}

\author{
By VIOLET I. RUSSELL, M.D., B.S.
}

An Address delivered before the Medical Society for the Study of Venereal Diseases, on Friday, January 29th, I926, at II, Chandos Street.

I AM painfully conscious that in this paper of mine I am presenting nothing that is worthy of the occasion. I have come to-night to this meeting, as I always do, to learn and certainly not to presume to teach. Still in my association for the last four years with the Venereal Department of Guy's Hospital, I have not been able to help gaining a certain acquaintance with the manifestations of gonorrhœa in the female, and the Directors of the department-Mr. Lloyd and Dr. Rawlins-have kindly allowed me to make use of the notes of some of the cases in preparing what I have to say to-night. Two things have made a great impression on me in this work. The first is the extraordinary amount of variation possible in the physical signs of a case of gonorrhœa from day to day. The second is perhaps a more controversial one, and that is that in my opinion practically every case of urethritis and the vast majority of cases of cervicitis are due primarily to the gonococcus. I acknowledge that in many cases I cannot prove this contention by demonstrating the gonococcus, but in a great many doubtful cases it can be found if looked for on many different occasions with perseverance, especially after the discharge has been cured ; the presence of secondary septic organisms masked its presence before. In a healthy woman (I purposely omit the weakly or phthisical type) the vulva is very resistant to septic infection-it would indeed be strange if it were not, as nature has placed it in such close proximity to the anus - and the most serious damage wrought by the gonococcus is the way in which it renders the tissues susceptible to infection. A primary septic vulvitis undoubtedly may occur in a weakly woman as a sequel of an attack of diarrhœa, but these attacks are usually so 


\section{URETHRITIS AND CERVICITIS}

evanescent and subside so quickly with ordinary cleanliness that it is not very often that the patient seeks medical advice. Such an infection, so far as I know, will not spread to the vagina.

A primary urethritis is said to occur occasionally secondarily to a Bacillus coli pyelitis, but this diagnosis should only be made after carefully excluding the gonococcus by bacteriological examination. On the other hand I have come across three cases of a Bacillus coli pyelitis complicating an attack of gonorrhœa without any intervening cystitis, and should like to know whether others have had the same experience.

When one has a case of vaginal discharge sent for diagnosis - after paying great attention to the historyand also incidentally to the way in which the patient tells that history-one examines the vulva, keeping the fact in mind that the gonococcus tends to burrow below the surface, and so paying especial attention to the orifices of Bartholin's ducts and to the urethra and its ducts. This urethra may appear entirely normal, but when one milks it to the orifice, applying gentle massage through the vagina, a drop of either mucid or purulent secretion may appear. If this happens the case is suspect, and even if films are negative must be seen again and preferably after some provocative manœuvre to obtain a reaction. If there is any redness of the mouths of the para-urethral ducts, or if any secretion can be expressed from them, the same suspicions are aroused.

$A$ cervicitis presents more difficulties in making a diagnosis as to its cause, for here sepsis after the lacerations of a confinement in a parous woman is a possibility. One must also remember that there is a distinct class of gonococcal infection where the cervix is badly eroded, but the urethra is apparently unaffected and never shows any signs. The diagnosis between the two can only be made microscopically, and if the case is a chronic one a great many films must be examined before one is satisfied that the case is not gonococcal in origin. Often gonococci are only found after the septic discharge has been cured. Films should be taken of course from the interior of the cervix and immediately after menstruation ; in a doubtful case it may be as well to paint the cervix with an irritant such as $\mathrm{I}_{5}$ per cent. $\mathrm{AgNO}_{3}$ on the previous day; a provocative dose of gonococcal vaccine may also be given. 


\section{BRITISH JOURNAL OF VENEREAL DISEASES}

I should like to add that films may be positive from the rectum when consistently negative from cervix and urethra, even when there have been no symptoms or signs of proctitis ; this was pointed out to me by Dr. Rawlins, and is often a help in diagnosis.

In a nulliparous woman a cervicitis is always very suspicious of a gonococcal infection, and especially if the endocervix is principally affected. An os which without any obvious ulceration bleeds on touch usually indicates the presence of the gonococcus, and a granular wormeaten condition of the os is also very suggestive. The diagnosis from a new growth is easily made by the difference in the feel of a velvety erosion and a hard friable neoplasm. Tuberculous ulceration of the cervix is exceedingly rare - it is characterised by loss of tissue resembling a carcinoma far more closely than a cervicitis, and is, I believe, always accompanied by signs of tuberculosis elsewhere. A primary chancre on the cervix must be remembered, although it is also a rare condition. It affects the vaginal aspect of the cervix, and is harder than an erosion. When in doubt, serum from its surface should be examined for spirocheta pallida.

The diagnosis of gonorrhœa in a pregnant woman may be very difficult as the normal vascularity of the parts at this time causes a congestion and excess of mucid discharge which may be very difficult to distinguish from an early gonorrhœa. The condition of the urethra may help ; then in a gonococcal case the interior of the os is a little more congested than the rest of the cervix; if scarlet granulations are visible inside the patulous os gonococci will probably be found. But the diagnosis must be made bacteriologically, and if there is no septic discharge there will probably be no difficulty in finding the gonococcus if it is present. The acute gonococcal infection during pregnancy with granular vaginitis and a profuse purulent discharge which one met with during the war is very seldom seen nowadays.

But although in the large majority of cases I am inclined to think that most really energetically pursued investigations end in the tracking of the gonococcus, still one must acknowledge that there are a tremendous variety of types of gonorrhœa.

I have taken out seventy-one cases of gonorrhœea from those attending the Guy's Hospital Clinic, and these 


\section{URETHRITIS AND CERVICITIS}

can be grouped into several distinct classes, which may be: of some slight interest.

The first patient was in a class by herself-a class in which there were no symptoms or physical signs of gonorrhœa, but the gonococcus was present. She was a married woman in the late thirties who came because her husband was attending with acute gonorrhœa, and was afraid that she had been infected. She had had seven children, and had never had a discharge at any time in her life. The vulva was entirely normal ; no redness of Bartholin's or the para-urethral ducts, no discharge from the urethra. The cervix was also entirely normal-no congestion-just a little mucus in the os. Films. were positive for gonococci. in both urethra and cervix. No signs ever developedshe was seen at different times by three of us working in the department, and we all made a note that the condition was normal. I am almost inclined to call her a. gonococcus carrier rather than a case of gonorrhœa. Films were again positive at the end of five months. She has now been negative for a year after provocative tests. She was treated by local swabbing with 25 per cent. sulphur in glycerine and a stock gonococcal vaccine.

In the next two cases there were slight physical signs. in the cervix, but no symptoms. The patients had both attended at once directly their husbands had developed the disease. In both cases the vulva and urethra seemed entirely normal and remained so. In one there was a slight cervical erosion; in the other there was no erosion, but the os looked a little patulous and granular. In neither case was there any discharge ; in both films were positive from the cervix only. The case with the eroded cervix developed a more acute erosion, and was rather slow to heal, but she never developed any symptoms, and there was never enough discharge from the erosion for her to notice it. The other case cleared up very quickly, and in a few weeks all appeared entirely normal.

Now we come to the class of the early aseptic case of gonorrhœa, and in that class I have got ten cases.

On examining the vulva there was sometimes nothing but a little clear mucus from the urethra on massage, sometimes a congestion-pink rather than red-of the urethra and the same spot of colour at the orifices of both of Bartholin's ducts. The cervix often felt and looked very like an early pregnancy; there was the same bluish 


\section{BRITISH JOURNAL OF VENEREAL DISEASES}

discoloration and excess of mucus. In other cases there was a small erosion round the os. One of the patients came complaining of slight vulval irritation ; most of the others had noticed a slight leucorrhœea. Some attended because they had run a risk of infection, but had not noticed anything wrong. All these cases had gonococci present in the films, and nearly all at the first examination.

The after-history of these patients is rather interesting when compared to the next class. All attended for treatment regularly in spite of their lack of symptoms, and all have done very well. They were all patients who paid attention to personal cleanliness, and were careful to carry out any directions given to them.

The next class is the typical acute gonorrhœa of the text-books, and of these I have fifteen cases. The urethra was red and œdematous with purulent discharge from all its ducts. The cervix was odematous with a scarlet everted os and profuse purulent vaginal discharge. These patients only attended when they were obliged to do so by the discomfort of the excoriation and soreness caused by the discharge. Nearly all of them were single girls, and nearly all belonged to a much lower type and a dirtier class than the other cases I have mentioned. There were exceptions, but only one or two.

It was much more difficult to find the gonococcus in these cases. Only five out of the typical fifteen cases were positive in the first two films taken. Two were positive two months after regular treatment, when the discharge had greatly improved. One was positive for the first time when all signs had disappeared and she was merely being kept under observation.

This acute class, as a class, was unsatisfactory in its attendance. When the discharge improved too many of the patients had a tendency to stay away until a too free indulgence in alcohol or some other indiscretion caused a relapse and brought them back in nearly as bad a condition as they were at first.

I now have left 43 cases of chronic gonorrhœa among this small series. I have divided these up into those with discharge but no hyperæmia, those with hyperæmia but no obvious discharge, and those with both congestion and discharge.

The first class-those with discharge but no local congestion-were the most favourable as regards treatment. 


\section{URETHRITIS AND CERVICITIS}

The first two cases had signs in the urethra alone. Both were examined because their daughters had developed an infective vulvo-vaginitis. Both were of a respectable, clean type, and both were anxious to be examined, but were sure they had never had any discharge. In both cases all that was to be found was a little purulent urethral discharge on massage. Films were positive. The cervix was apparently quite normal in each case. Both of these patients cleared up very quickly.

A third patient was also only examined because her child had gonorrhœa. In this case all looked perfectly normal on the first examination, but for a slight excess of mucus from the cervix. Gonococci were present. On the second occasion, which happened to be after menstruation, the cervix was slightly red round the os. This patient gave a history of pelvic trouble some years previously.

Another patient - a nullipara-came up for a test giving a history of gonorrhœa seven years before, and saying that she still had an occasional leucorrhœa. The urethra felt indurated, but showed no discharge. There was a slight white cheesy vaginal discharge. The note of the cervical condition was "Cervix almost normal, slight redness of the os on the anterior lip." Cervical films were positive. Perhaps I should not have included her here because of that redness of the os, but on other occasions the cervix appeared quite free from congestion.

Another patient some months after a course of treatment showed nothing but a little white mucus from the urethra and a cheesy white vaginal discharge, but gonococci persisted.

I now come to two cases with a ring of red or purple congestion round the urethra and the os but no breach of surface of the mucous membrane. From the distribution of these signs I am inclined to consider them as evidence of an old attack of gonorrhœa ; if they were only senile changes one would expect parts of the rest of the vulva and possibly the vagina to be also affected. One of these two cases was examined because her child had a vulvovaginitis of some years' standing. She was past the menopause. Several films were negative, and she did not look as if she were then in an infective condition.

The other case was examined because she had chronic rheumatism. She had a granular shiny red urethral meatus and a similar zone of redness round the os. Films 


\section{BRITISH JOURNAL OF VENEREAL DISEASES}

were negative. I treated her because her rheumatism was suggestive, and she said the rheumatism much improved, but I'm not at all sure that there wasn't an element of suggestion in it ! The cervix certainly lost its granular look with treatment and became merely an innocuous-looking pink colour.

Now I come to the comparatively large class-thirtysix cases in all, with chronic discharge and hyperæmia of the urethra or cervix or both-and this class has two subdivisions.

In the more favourable type as regards treatment the affected mucous membrane looks rough and granular, and the redness is confined more or less to the urethra and its ducts, Bartholin's ducts and the cervix. There may often be red macules scattered over the vulva, but most of the vulva and the vagina are unaffected. In the other type there is a general congestion of the vulva and vagina as well as the primary sites of infection and the mucous membrane is red and shiny, sometimes almost resembling a senile condition, while there is a profuse mucid or mucopurulent discharge. This chronic hyperæmia I have often found very difficult to clear up satisfactorily.

In the first of these classes I have twenty-six cases. Fourteen of them showed redness and a little discharge, either muco-purulent or purulent from the urethra, some endocervicitis, a granular condition round the os and a purulent vaginal discharge. In twelve out of the fourteen cases the para-urethral ducts were affected. In nine out of the fourteen gonococci were demonstrated, but often not for some months.

In seven other cases the cervix looked more or less normal, but there was bleeding from inside the os when films were taken from the cervix. It is rather strange that all these seven cases were positive for gonococci from the cervix. A bleeding erosion on the vaginal cervix on the other hand usually means a secondary streptococcal infection.

The condition of the urethra sometimes becomes definitely caruncular. One patient had first come to surgical out-patients complaining of hæmaturia. She had been treated for gonorrhœa some years previously, but had thought herself cured. There were granulations inside the urethra which bled quite profusely on touch. She soon improved on treatment with collosol argentum pencils, and the urethra eventually became quite normal. 


\section{URETHRITIS AND CERVICITIS}

Another patient had a general caruncular condition of the urethra - it was inflamed and everted with discharge from all its ducts. After patient irrigation of these ducts the condition cleared except for a definite caruncle that remained on the lower lip of the meatus, and this was removed by two applications of the thermo-cautery under cocaine anæsthesia.

One other patient was also much benefited by a cauterisation, though she remained more or less congested at the meatus.

Two other patients with caruncular urethræ were left with a shiny discoloration of the orifice, which seems as if it will be permanent-there is no urethral discharge.

I now have left ten cases of the congestive type of chronic gonorrhœe. In these cases the whole vulva, vagina and cervix are red and congested-no cervical erosion, but a patulous os and a marked excess of cervical discharge. Eight out of the ten cases have been positive for gonococci. The urethra shared in the general congestion, but was not markedly affected, and showed no thickening. There was no hypertrophy or œdema of the vulva-merely general redness.

I have seen several cases of a mild vaginitis after the use of quinine pessaries which rather closely resembled this type of gonorrhœa, and sometimes the irritation caused by using too strong an antiseptic douche will cause much the same appearance ; but a patulous os in a nullipara is suggestive of gonorrhœa.

So far I have found that these cases do best on tampons of ro per cent. ichthyol in glycerine as a soothing application. I have not found vaccines of much effect, but injections of collosol manganese occasionally help. I should be very grateful for suggestions. Most of the cases I have seen belonging to this type are young unmarried girls of the typist class who seem to be doing all they can to help towards a cure.

It has been said-and it would not be remembered were there not just a modicum of truth in it !- that it makes no difference to a case of gonorrhœa in the female how you treat it-it will clear up or will not clear up in its own time. But no one would say that the way the patient treats herself makes no difference-and this aspect strikes one very forcibly in a venereal clinic. Two points that need stressing are firstly the importance of attending to the 


\section{BRITISH JOURNAL OF VENEREAL DISEASES}

patient's general health, and secondly the need to warn her, if possible, never to get overtired or overheated. One doesn't want her to brood over her complaint, but a more or less sedentary life for a few months will give her a much better chance. The ideal treatment at first of course is rest in bed. I feel sure that active exercise, such as tennis, is exceedingly dangerous for a patient with active gonorrhœa, and is exposing her to the risk of a salpingitis. One girl attending the clinic who complained of constant attacks of pelvic pain and in whom both tubes were tender to palpation, though not obviously enlarged, said that the pain left her directly she gave up her dressmaking work, which involved the use of a treadle machine, and got a position as a clerk. Her general health obviously improved greatly after this time.

The patient with gonorrhœea should avoid getting hot as much as possible. Several hospital patients who are cooks have told me that the discharge always diminishes in amount when they get a day off duty away from the kitchen fire. I must acknowledge, however, two cases which did very well in spite of outside conditions seeming unfavourable. They were both dancing instructresses at night clubs, and as well as being on their feet in a hot atmosphere all the night, they also felt obliged to take a certain amount of alcohol when offered it for the sake of the profits to the management. I attribute their cure partly to their attending regularly for treatment, but also and to a great extent to their care as regards personal cleanliness. I can't help thinking that the infrequent washing of the average hospital patient is one of the chief reasons why they usually take niuch longer to cure than the private patient.

As regards the local treatment, patience and perseverance are necessary. I do not believe that there is any rapid and certain cure for gonorrhœa except for possibly a few cases which come in the very early stages. One can prevent the patient getting complications; one can clear up the discharge; but a long period of observation is necessary before one can say that the gonococcus itself has been eradicated. The septic organisms are in the discharge and on the surface of the epithelium-they can be got rid of with some confidence-but the gonococcus burrows deeply into the cervical crypts and may 


\section{URETHRITIS AND CERVICITIS}

lie latent for a long period. I have seen many cases of chronic gonorrhœa who had been told that they were cured after a course of treatment many years before, and I am uncomfortably conscious that in my own optimistic youth I discharged many cases distinctly too soon.

I should like to mention three cases in this connection as illustrations. One came to the hospital giving a history of gonorrhœa three years before for which she had received a course of treatment and was considered cured. She now came as she wished for a test before marriage. The urethra was apparently normal. There was some white mucoid vaginal discharge and rather a ragged granular condition inside the os which was more patulous than normal. Films were positive from the cervix.

The next patient was a case that I had considered cured. She was primarily a case of Bartholin's abscess and cervicitis due to a marital infection. She was treated in the routine way by swabbing and vaccine; she was kept under observation for several months, had six negative provocative films, and the urine was negative, and then went away for a year. On her return to London she came to see me, was very cheerful, and said that she had kept perfectly well with no discharge. What is more, the local condition looked quite normal, but to my great distress quite definite gonococci were present in the cervical films.

Another patient had positive films nine months after she had stopped treatment. Before the positive films she had had six negative films taken after previously painting the cervix with $\mathrm{AgNO}_{3}$, and some of these after taking alcohol. She had no symptoms beyond a slight irritation for three days before the positive films were taken.

I don't think for a minute either of the two last cases were due to reinfection, and cases like these make me very chary of discharging a patient as cured before a prolonged period of observation and a good many provocative tests.

Although it is often impracticable I like to aim at completely clearing up every case of discharge which was originally gonorrhœal, even if the final stage is purely a leucorrhœa.

The routine local treatment at Guy's Hospital (provided that the patient has not an acute vulvitis, in which case no instrumentation is attempted until this has subsided) consists in first swabbing the vulva with the anti- 


\section{BRITISH JOURNAL OF VENEREAL DISEASES}

septic solution chosen, then inserting a warmed and oiled Fergusson speculum, removing all discharge visible, swabbing the cervix, treating the endocervix with a dressed Playfair's probe, removing the speculum, examining and swabbing the vagina during removal, and then treating the urethra first with a dressed probe, and subsequently irrigating all the para-urethral ducts which show any sign of infection. Bartholin's ducts are treated in the same way if necessary. This para-urethral irrigation has a striking effect in relieving any soreness or irritation which the patient may have felt in the region of the urethra, and also in several cases clearing up a rheumatic manifestation of the disease elsewhere. The irrigation may have to be kept up for some time, as the ducts discharge irregularly, but I have always found that the patient is anxious for it to be kept up, and says that it leaves her feeling much more comfortable.

I have not seen the electro-cautery used to obliterate these ducts, but it seems to me that it would be difficult in some cases to be sure of obliterating the whole tract, which is often from $\mathrm{I}-2 \mathrm{~cm}$. in length, and capable of containing quite a large amount of secretion. I would not want to run any risk of merely closing up the orifice.

The antiseptics one can use for local treatment are of course many. It is better not to employ anything irritating to the cervix-unless there are hypertrophic granulations which need to be treated with a caustic, such as iodised phenol. One cannot kill the gonococci in the crypts by painting on a strong irritant, and it merely damages the tissues.

We find that a glycerin basis is preferable to a watery one, and ro per cent. protargol in glycerine still holds its own at the Guy's clinic as the most effective treatment in cases of acute and subacute gonorrhœa. In the chronic cases 25 per cent. sulphur in glycerine sometimes acts almost miraculously - other cases do better with ichthyol. Picric acid in glycerine is often useful, though in a few cases it may irritate the tissues. We gave acriflavine and glauramine a trial, but without being greatly impressed, although a few cases, which seemed to be the ones without much mucus in the discharge, did well on these. In a few cases we insert cervical bougies into the cervix ; we only use tampons in the more severe cases. Lately we have been trying some gas-producing 


\section{URETHRITIS AND CERVICITIS}

pessaries and bougies with rather encouraging results. For irrigating Skene's ducts a watery solution of protargol has been most often used. This irrigation is carried out with a hypodermic syringe and a blunt-pointed needle of the type described by Dr. Rawlins, and if necessary with the help of a Parnell meatal speculum. It must be carried out carefully; in one case I pricked the interior of the duct and caused a septic induration around that side of the urethra which has never entirely disappeared.

The patients use medicated pessaries themselves at home. Frequent sitz baths are recommended, but they are told not to douche owing to the risks of septic apparatus and of giving the douche at too high pressure. In some cases the patient can also use urethral pencils if necessary themselves, but if these are made up in glycerogelatine, which is the best medium, most patients find them too difficult to insert, and if made up with cocoabutter to give a stiff pencil, they may damage the urethra. We find it better for the majority of the patients not to let them attempt urethral treatment. Every patient with a urethritis is put on to a mildly urinary antiseptic and diuretic mixture.

Gonococcal vaccines, either a stock vaccine or the detoxicated varieties, are used in nearly every case. In the case of the stock vaccine we only use comparatively small doses, commencing at about 5 millions in a chronic case, and as little as I million in an acute case, and continuing, if necessary, until a dose of about Ioo millions is reached. We leave a week's interval between each dose, even if there has been no reaction. Diathermy has been used in a few cases, but without very marked success, and I have had no personal experience of it.

These are the methods of the Guy's clinic, and I am not going to attempt to discuss other methods now. I have not sufficient experience of them, and it will be much better to hear of them from other members who have. I should be especially interested to hear if any one has tried any of the suction instruments devised for the cervix, as the idea rather attracts me! 